\title{
Formation of an integrated approach and analysis of the assessment of the urban planning value of the territory
}

\author{
Natalia Abdukhanova*1[0000-0002-8513-3106], Andrey Kulkov1[0000-0001-8378-1858],

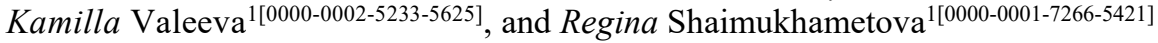 \\ ${ }^{1}$ Kazan State University of Architecture and Engineering, 420043 Kazan, Russia
}

\begin{abstract}
The article is devoted to the study of existing methodologies of urban planning value appraisal. This article provides a definition of urban planning value and examines the factors that influence it. The existing methods of determining urban planning value are studied and analysed, and examples of calculating urban planning value are given.
\end{abstract}

Keywords. Urban planning value, factors of urban planning value, value of the territory appraisal methodology.

\section{Introduction}

The definition of the urban planning value of the territory is carried out in order to solve the problems related to the rational and efficient use of the territory: the functional division of the territory, the organization of space-planning decisions, the calculation of the economic efficiency of the territory for construction.

The urban planning value of a territory is based on three concepts of economic theory: «price», «cost» and «value».

In International Valuation Standards, the concept of «value» of a land plot is determined by its utility or ability to meet the needs and requirements of people [1], uniqueness, location, durability, degree of limited supply, and specific utility of a particular land plot [1,2].

The Land Code of the Russian Federation uses the concepts of «market value» and «cadastral value» of land plot when evaluating land plot (article 66 of the Land Code of the Russian Federation) [3]. The content of these concepts is given in the Valuation Act [4].

Thus, the «market value» of a land plot is defined as the most probable price at which the object of valuation can be alienated on the open market in a competitive condition [5], when the parties to the transaction act reasonably, having all the necessary information, and the price of the transaction is not affected by extraordinary circumstances.

«Cadastral value», in turn, in the Valuation Act is defined as the value established as a result of a state cadastral valuation or as a result of consideration of disputes on the results of establishing the cadastral value, or determined in other cases as required by the law [6].

\footnotetext{
*Corresponding author: ab-natali@yandex.ru
} 
In addition to the previously identified types of value used in the appraisal of land plots [7], there is one more - investment value. Its definition is also given in the Valuation Act. The investment value is defined as the value of the object of appraisal for the subjects of investment, determined for the investment purposes of using such an object [8]. The same definition is given in the Federal Valuation Standard «The purpose of valuation and types of value» (FVS No. 2). In Federal Valuation Standard No. 13 («Determination of Investment Value»), the investment value is defined as the amount of funds reflecting the beneficial effect of using the valuation object for a specific person or group of persons when this person(s) establishes the investment goals of using the valuation object [9].

«Price» as a result of valuation activities in the Federal Valuation Standard «General Valuation Concepts, Approaches and Requirements for Conducting Valuation» (FVS No. 1) is defined as the amount requested [10], offered or paid by participants in a completed or proposed transaction. The same concept is given in the Methodological Instructive Regulations on the State Cadastral Valuation for the Price of a Land Plot.

The term «value» initially has a more abstract character, most often used in philosophy, psychology and economic theory [11]. This concept is more the result of the subjective perception of the subject than it differs from such a category as «cost», which has clear and defined meanings [12].

In the Methodological Recommendations on development of urban zoning schemes, the concept of urban planning value is defined as «a measure of the ability of a territory to meet the necessary social requirements for its condition and use» [13].

Summarizing the above definitions of the categories «cost», «price», «value» and «urban planning value of the territory», we can draw the following conclusions:

1) «price» of a land plot is a particular definition of the concepts «cost» and «value». The price category according to the time parameter for the implementation of purchase [14] and sale transactions can be divided into the offer price («pre-trade») and the negotiated price;

2 ) the «cost» of a land plot is not always equal to the «price» of a land plot. Market, cadastral and investment values are used to determine the value of a land plot.

3 ) the concept of «value» includes the categories «price» and «cost».

4) «urban planning value» expresses the degree of usefulness of the territory, including various categories of the value of land plots, being a broader definition of the category of «value».

\section{Methods}

We shall consider urban planning value of a territory appraisal methodologies based on the matrix mechanism of integrated assessment.

It is known that a person is not able to reasonably make complex decisions on tasks that require taking into account many factors, without using backup tools. The use of matrix mechanisms of integrated assessment helps in solving such complex problems. It formalized the individual attitude of a person to the factors influencing decision-making [15].

The procedure of the matrix mechanism of integrated assessment is reduced to bringing the characteristics of the territory described in qualitative terms, to the scale of criteria «1-4», where 1 - unattractive, 2 - low attractiveness, 3 - medium attractiveness and 4 - high attractiveness [16]. After that, binary convolution matrices are formed, which show the attitude of a person to a pair of compared parameters.

To determine the urban planning value of the territory, D.N. Krivogina formed a model, the main components of which are social infrastructure, road infrastructure, transport infrastructure, public safety and the prestige of the area [17]. In turn, we will divide each of the components into subcomponents. Let us represent the dependence of these components in the form of a binary convolution matrix (Fig. 1). 


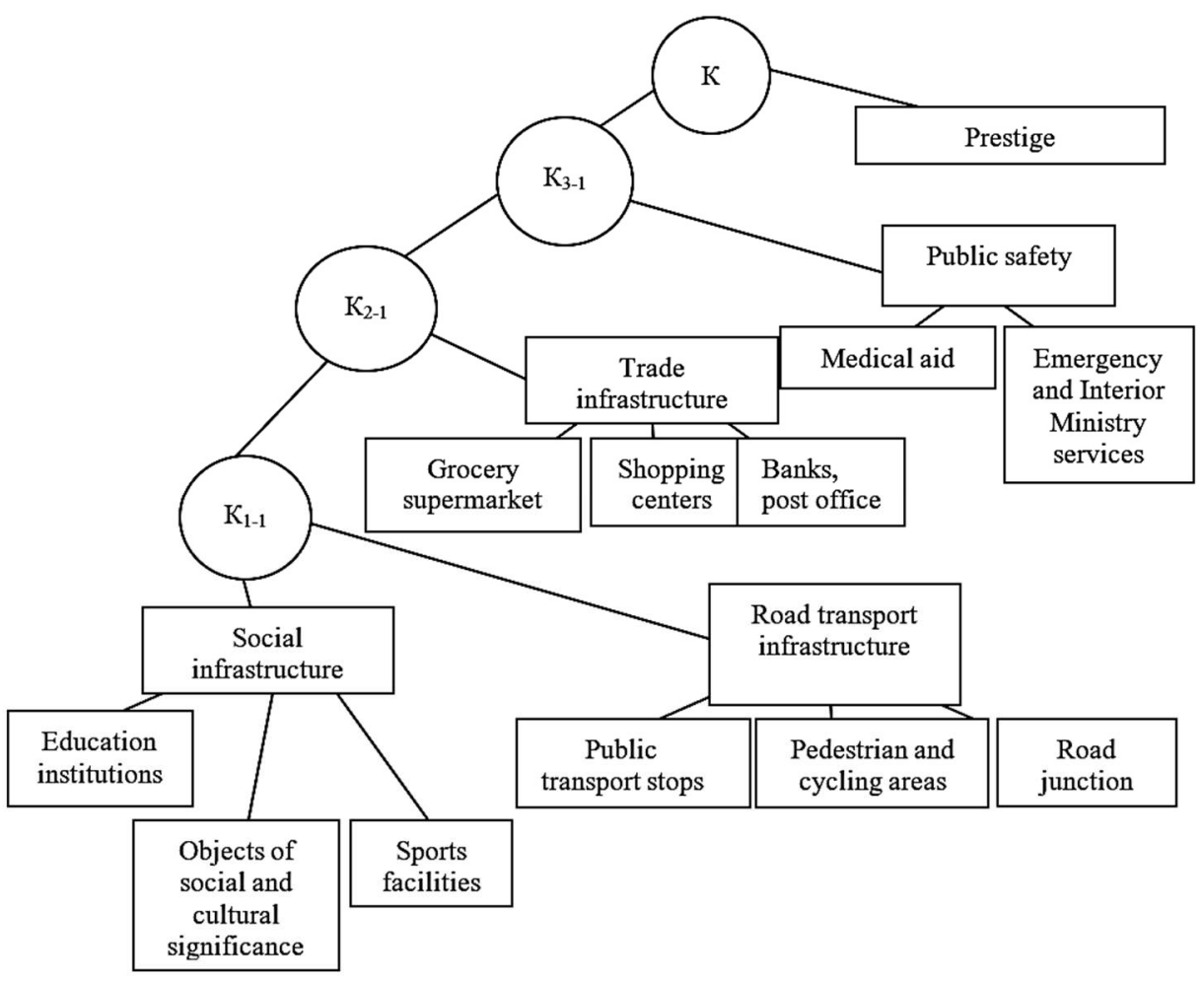

Fig. 1. The structure of the model that determines the urban planning value of the city district [17].

\subsection{Urban Planning Value Appraisal Methodology No. 1}

According to the methodology of urban planning value appraisal No. 1, it is necessary to find integrated assessments of the model's components by constructing a reduction function based on an average assessment of the consumer attractiveness of factors. To do this, as a factor of the attractiveness of the territory let us estimate the travel time from the assessed territory to the infrastructure facility: walking time of more than 30 minutes is an unsatisfactory location of the territory, less than 5 minutes is excellent location. Let us present the reduction function for estimating the territory in the form of the following formula (1):

$$
T=(-3) / 25 \times(t-30)+1 \text {, }
$$

where $T$ is an integral assessment of the provision of the territory with infrastructure facility;

$t$ is average walking time from the assessed territory to the infrastructure facility.

All infrastructure facilities included in the model components are highlighted on a map of the area to determine the average travel time to the infrastructure facility. Then the travel time to each facility is calculated, the obtained time values are summed up, and their arithmetic mean value is calculated:

$$
t=\left(\sum_{i=1}^{n} t_{i}\right) / n,
$$

where $t_{i}$ is the travel time from the assessed territory to the $i$-th facility;

$n$ is the number of infrastructure facilities.

After that, the integral value of integrated assessments of the territory is determined by applying the linear convolution mechanism. Linear convolution in this case is used due to the fact that the estimated factors of the urban planning value of the territory in terms of consumer 
significance are at the same level, which makes it impossible to put ranks according to their significance.

Thus, the mathematical model of integrated territory assessment will have the following form (formula 3):

$$
I T A=\sum_{i=1}^{n}\left(K_{i} \times T_{i}\right)
$$

where $K_{i}$ is weighted coefficients determined by the subject based on his preferences, while the condition $\sum_{i=1}^{n} K_{i}=1$;

$T_{i}$ is integral integrated assessments of the walking distance of the territory's objects.

\subsection{Urban Planning Value Appraisal Methodology No. 2}

Urban planning value appraisal methodology No. 2 is based not on the assessment of the distance of the assessed territory from infrastructure facilities, but on the number of such facilities within a walking distance.

The integral value of integrated assessments of the equipment with infrastructure facilities within walking distance from the assessed territory can be determined by the formula (4):

$$
I T A_{i}=n-1
$$

where $n$ is the number of infrastructure facilities within walking distance.

However, if $n \geq 4$, then the assessed territory has excellent equipment with infrastructure facilities, $n=3$ - good equipment, $n=2$ - satisfactory equipment, $n \leq-$ unsatisfactory equipment.

After that, model component integrated assessments are calculated in accordance with formula (3).

As an example, let us estimate the urban planning value of a land plot for the educational institutions' subcomponent of the social infrastructure component using two methodologies. The land plot is located in the microdistrict of Azino-1, Kazan.

First, let us select all the sports facilities located in the microdistrict, and determine the walking distance in minutes to these facilities from the assessed land. According to the first methodology, it is necessary to count all education institutions. There is no need to take into account all facilities for the second methodology. It is necessary to take into account the facilities that are within walking distance.

Let us determine the selection radius to appraise the urban planning value of the territory for residential development in the microdistrict of Azino-1 in Kazan. It is necessary to determine the average time of crossing the microdistrict. We make two measurements of the microdistrict crossing in two directions: from north to south and from west to east. Thus, the average time of crossing the microdistrict will be 15-45 minutes, then the radius will be 15 minutes. For facilities which walking distance exceeds this radius set «-». For example, let us define this indicator for schools. The results of determining the walking time to schools from the assessed land plot are shown in Table 1.

\begin{tabular}{|c|c|c|c|c|c|c|c|}
\hline \multirow[b]{2}{*}{$\begin{array}{l}\text { Address of the } \\
\text { land plot }\end{array}$} & \multirow{2}{*}{$\begin{array}{l}\text { Methodology: } \\
\text { Methodology } 1 \\
\text { (M1) } \\
\text { Methodology } 2 \\
\text { (M2) } \\
\end{array}$} & \multicolumn{6}{|c|}{ School number } \\
\hline & & 161 & 167 & 169 & 171 & 174 & 175 \\
\hline \multirow{2}{*}{ Zakieva str. } & M1 & \multirow{2}{*}{5} & \multirow{2}{*}{7} & \multirow{2}{*}{13} & 19 & 20 & 28 \\
\hline & M2 & & & & - & - & - \\
\hline
\end{tabular}

Table 1. Selection of walking distance from the selected land to schools, min.

In the same way, we will count the number of kindergartens located in a given microdistrict (Table 2). 
Table 2. Selection of walking distance from the selected land to schools, min.

\begin{tabular}{|c|c|c|c|c|c|c|c|c|c|c|c|c|c|c|c|c|c|c|}
\hline \multirow{2}{*}{$\begin{array}{l}\text { Address } \\
\text { of the } \\
\text { land plot }\end{array}$} & \multirow[b]{2}{*}{ Methodology } & \multicolumn{17}{|c|}{ Kindergarten number } \\
\hline & & 127 & 408 & 272 & 261 & 180 & 60 & 48 & 39 & 185 & 64 & 109 & 67 & 113 & 103 & 68 & 181 & 40 \\
\hline \multirow{2}{*}{$\begin{array}{c}\text { Zakieva } \\
\text { str. }\end{array}$} & M1 & \multirow{2}{*}{5} & \multirow{2}{*}{7} & \multirow{2}{*}{11} & \multirow{2}{*}{10} & \multirow{2}{*}{10} & \multirow{2}{*}{14} & 16 & 18 & 16 & 16 & 21 & 26 & 25 & 26 & 23 & 25 & 32 \\
\hline & M2 & & & & & & & - & - & - & - & - & - & - & - & - & - & - \\
\hline
\end{tabular}

Next, let us determine the average walking time from the assessed land plot to all education institutions and the integral assessment of the provision of the area (Table 3).

Table 3. Integrated assessment of the walking distance of facilities by methodologies No. 1 and No. 2 .

\begin{tabular}{|c|c|c|}
\hline Destination facilities & $t, \min$ & $T$ \\
\hline \multicolumn{3}{|c|}{ M1 } \\
\hline Kindergartens & 17.71 & 2.47 \\
\hline Schools & 15.33 & 2.76 \\
\hline \multicolumn{3}{|c|}{ M2 } \\
\hline Kindergartens & 9.5 & 3.46 \\
\hline Schools & 8.33 & 3.60 \\
\hline
\end{tabular}

Let us assume that the availability of kindergartens and schools has the same value for the consumer, then we will assign the same weighted coefficients for each type of facility: $K_{l}=0.5, K_{2}=0.5$. Let us determine the final result of integrated assessments (formula 5):

$$
I T A=K_{1} \times T_{k}+K_{2} \times T_{s c} .
$$

Thus, the assessment of the convenience of the location of the assessed territory in relation to education institutions using methodology No. 1 was 2.62 points, and using methodology No. 2 was 3.53 points.

Similarly, the urban planning value of the territory is assessed using other components of the model.

\subsection{Delphi methodology}

This methodology was proposed by I.V. Sychev. Urban planning value of the territory appraisal is proposed to conduct through a point system as in the previous reviewed methods because it is not possible to express the value of the territory in monetary units.

I.V. Sychev identifies the following groups of factors for assessing the urban planning value of the territory:

1) external factors that are not directly related to the territory, but affect its urban planning value;

2) factors of market value of the territory;

3) factors of ecological value of the territory;

4) factors of the transport value of the territory;

5) factors of infrastructure availability of the territory;

6) factors of legal, land management and urban planning availability of the territory;

7) physical parameters of the territory;

8) financial potential of the project implementation of the territory integrated development [18].

Each group of the above factors has a different value for the users of the territory. Consequently, it is necessary to conduct an expert survey to determine their weighted coefficients. In this case, the survey can be carried out by interviewing. 
Thus, the integral value of the urban planning value of the territory can be calculated through the following formula (6):

$$
I_{\text {urb.value }}=\sum_{i=1}^{n} x_{i} \times w_{i}
$$

where $I_{\text {urb.value }}$ is integral value of the urban planning value of the territory;

$x_{i}$ is value of the estimated factor, points;

$w_{i}$ is weighted coefficient of the factor, $\%$.

As an example, the evaluation of the significance of the urban planning value factor can be calculated based on a five-point scale, where the score of 5 is assigned to a factor with a very high impact, 4 - above - average impact, 3 - moderate impact, 2 - below-average impact, 1 - very low impact. Expert assessments are summed up to determine the weighted coefficient for each factor, the resulting value for each factor is divided by the total score of the group of factors to which the factor belongs.

The estimation of a particular factor of urban planning value is determined by the following formula (7):

$$
I_{i}=\sum_{i=1}^{n}\left[\left(I_{i, a c t} \times w_{i, f}\right) /\left(I_{i, \max } \times w_{i, f}\right)\right]
$$

where $I_{i}$ is the value of the private index of urban planning value of the territory by the estimated factor;

$I_{i, a c t}$ is actual value of the $\mathrm{i}$-th parameter, $\%$;

$w_{i, f}$ is weight value of the estimated factor;

$I_{i, \max }$ is the maximum sum of values of the estimated factor parameters taking into account their weight.

The integral values are estimated according to the formula (8):

$$
I_{\text {urb.value }}=\sum_{i=1}^{n}\left\{\left[\sum_{i=1}^{n}\left(I_{i, a c t} \times w_{i, f}\right)\right] /\left[\sum_{i=1}^{n}\left(I_{i, \max } \times w_{i, f}\right)\right]\right\} .
$$

The assessment results of the integral value of urban development can be interpreted as follows:

$I_{\text {urb.value }} \geq 0.75$ - high urban planning value of the territory;

$0.50 \leq I_{\text {urb.value }}>0.75$ - sufficient urban planning value of the territory;

$0.25 \leq I_{\text {urb.value }}>0.50$ - average urban planning value of the territory;

$I_{\text {urb.value }}<0.25$ - low urban planning value of the territory.

The integral index is a reflection of the urban planning value of the territory. The higher the index, the higher urban planning value and prestige of the land, respectively, and the cost. The lower the integral index, the lower the urban value of land, its prestige and cost [19].

\subsection{Methodology for assessing the value of the territory proposed by I.V. Grigoriev}

In the methodology of assessing the urban planning value proposed by I.V. Grigoriev assessment criteria form a tree, each level of which specifies the criteria of the higher level.

At the first level, there are such criteria for assessing urban planning value as urban planning value, social and functional value, and socio-economic value [20]. An additional criterion is the cadastral value [21]. This tree is shown in Fig. 2.

The methodology is described by the formula (9):

$$
I T A=\sum_{i=1}^{n} 1\left[V i \times\left(\sum^{n i j}{ }_{j=} 1\left\{V_{i j} \times\left[\sum^{n i j k}{ }_{k=l}\left(V_{i j k} \times l_{i j k}\right)\right]\right\}\right)\right],
$$

where $n$ is the number of tree branches outgoing from the node of the corresponding level (at the first level $n=4)$;

$V$ is the weight of the parameters of the next level in the node of the previous level;

$l$ is significance of factors that characterize the parameters of the value category. 
The methodology reveals urban planning features of unused land and determines the optimal functional purpose of built-up land from the point of view of technical, economic, social, ecological and architectural planning factors.

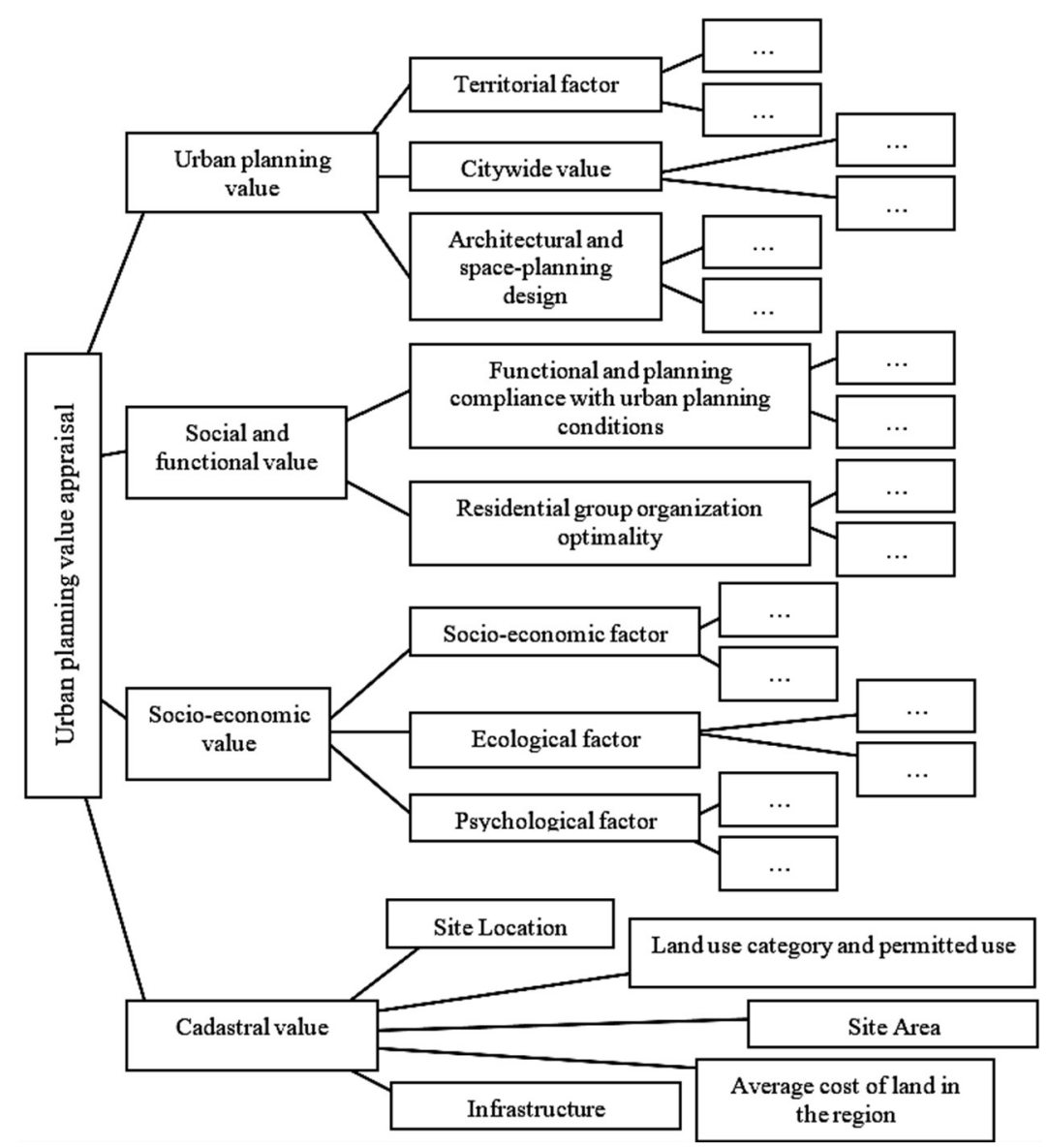

Fig. 2. Scheme of grouping criteria for assessing the urban planning value according to the methodology of I.V. Grigoriev.

\section{Results}

The urban planning value of a territory is one of the most important concepts that determine the quality of urban planning decisions.

Urban planning value of the territory appraisal is carried out in order to identify the most effective use of the territory and to maximize the benefits from the use of the territory.

In addition, a high-quality and timely assessment will allow for effective planning and management of the development of territories, which in turn will determine the level of socioeconomic development of the territory and its investment attractiveness.

Thus, in the current conditions of economic development, the assessment of the urban planning value of the territory is of key importance for developers, namely, it will reveal the urban development potential of the territory. 


\section{Discussions}

The following conclusions can be drawn as a result of the considered methodologies:

1) urban planning value is a qualitative indicator and cannot take the form of monetary units;

2) the result of any urban planning value of the territory appraisal methodology is a division of the city into functional zones, which are determined depending on the impact of factors of urban planning value of land plots;

3 ) greater value of the urban planning value of the territory as a result of the assessment suggests a greater ability of the territory to meet the requirements of users;

4) calculation of the urban planning value of a territory provides an opportunity to predict possible changes in the value of real estate objects in the assessed territory.

\section{Conclusions}

Thus, the authors analyzed the existing methodologies of urban planning value appraisal and the need to form an integrated approach to the assessment is justified. The advantages and disadvantages of each methodology are shown.

The formation of an integrated approach and timely analysis of the urban planning value appraisal will allow local governments to make the right management decision, as well as to develop an effective model for the use of the territory, to show the most valuable areas and make effective decisions regarding investments and other goals stipulated by law.

\section{References}

1. O. Kleshcheva, F. Sayfullina, N. Abdukhanova. Complex criterion for evaluating contractor's activities in the construction industry, IOP Conf. Ser. Mater. Sci. Eng. 890, (2020). DOI: 10.1088/1757-899X/890/1/012116.

2. E. Shagiakhmetova, O. Borovskikh, A. Nizamova, T. Kazymova. Multivariate model of construction project operational efficiency, IOP Conf. Ser. Mater. Sci. Eng. 890, (2020). DOI: 10.1088/1757-899X/890/1/012113.

3. J. Wang, W. Lin, Y.H. Huang. A performance-oriented risk management framework for innovative $R \& D$ projects, Technovation 30, 601-611 (2010). DOI: 10.1016/j.technovation.2010.07.003.

4. L.N. Ustinova, N.G. Abdukhanova, D.A. Ermolaeva. Typology of an enterprise's innovation potential, Creative Economy 14 (12), 3451-3464 (2020). DOI: 10.18334/ce.14.12.111206.

5. A. Brattström, J. Frishammar, A. Richtnér, D. Pflueger. Can innovation be measured? A framework of how measurement of innovation engages attention in firms, J. Eng. Technol. Manag. JET-M. 48, 64-75 (2018). DOI: 10.1016/j.jengtecman.2018.04.003.

6. L. Ustinova, R. Sirazetdinov. Factors affecting the parameters of the construction industry, IOP Conf. Ser. Mater. Sci. Eng. 890, (2020). DOI: 10.1088/1757899X/890/1/012117.

7. E.V. Ilina, A.I. Romanova. Operational services management in the context of sustainable development of intelligent technologies, IOP Conference Series 890, (2020). DOI: 10.1088/1757-899X/890/1/012183.

8. A.I. Romanova, G.M. Zagidullina, A.N. Afanasyeva, R.S. Hkairetdinova. Experience in the region to increase the availability of housing services, Mediterranean Journal of Social Sciences 6 (4), 549-554 (2015). DOI: 10.5901/mjss.2015.v6n4s2p549.

9. N.G. Abdukhanova, G.D. Kamaletdinova, G.R. Zainetdinova. Analysis of the probability of reducing risks in the investment and construction industry through the use of 
blockchain technology, Publishing house. Finance and credit 25 (8), 1907-1917 (2019). DOI: $10.24891 / \mathrm{fc} .25 .8 .1907$.

10. D.R. Zaynullina. The impact of the implementation of an innovative project on the effects arising in the internal and external environment, IOP Conf. Ser.: Mater. Sci. Eng. 890, (2020). DOI: 10.1088/1757-899X/890/1/ 012176.

11. O.V. Bakhareva. Development of the housing stock and urban infrastructure: energyefficient rehabilitation of an atypical apartment building, Creative Economy 6 (4), 487508 (2019). DOI: 10.18334/zhs.6.4.100436.

12. A.N. Afanasyeva, S.F. Fedorova. Availability of innovative housing from the perspective of sustainable construction, IOP Conference Series 890, (2020).

13. Methodological recommendations for the development of urban zoning schemes. MDS 30-1.99.

14. E.V. Ilina, A.I. Romanova, O.V. Maksimchuk, A.V. Voronin. Development of the construction industry in the context of import substitution: Russian experience, Espacios. 38 (48), 18 (2017).

15. T. Röth, P. Spieth. The influence of resistance to change on evaluating an innovation project's innovativeness and risk: A sensemaking perspective, J. Bus. Res. 101, 83-92 (2019). DOI: 10.1016/j.jbusres.2019.04.014.

16. V.A. Kharitonov, A.O. Alekseev. The concept of subject-oriented management in social and economic systems, Scientific Journal of Kuban State University 109 5, 690-706 (2015).

17. D.N. Krivogina et al. Appraisalr of urban planning value of the territoty, Master`S Journal 2, 69-79 (2019).

18. I.V. Sychev. Efficient use of land in integrated development projects. State University of Land Management, 194 (2019).

19. A.A. Kolomyceva. Development of the methodology for determining the cadastral value of real estate on the example of land settlements, Graduate qualification work on the department 21.04.02 // Land management and cadastre. Kuban, 198 (2017).

20. I.V. Grigoriev. Typological features of the formation of high-rise multifunctional residential complexes, (2003).

21. N.G. Abdukhanova, G.D. Kamaletdinova. Methodological peculiarities of determining the urban planning value of the territory, Eurasian Union of Scientists 3 iss. 60, (2019). 